\title{
ENSINO DE INGLÊS PARA FINS ESPECÍFICOS EM DOIS CURSOS DA UNIVERSIDADE ESTADUAL DE LONDRINA: RELATO DE EXPERIÊNCIA
}

\author{
TEACHING ENGLISH FOR SPECIFIC PURPOSES IN TWO UNDERGRAD \\ COURSES OF UNIVERSIDADE ESTADUAL DE LONDRINA: A CASE REPORT
}

Elisângela L. Liberatti ${ }^{1}$

RESUMO: O propósito deste artigo é fazer um relato de experiência do ensino de inglês para fins específicos em dois cursos de graduação da Universidade Estadual de Londrina: Jornalismo e Matemática Empresarial. As disciplinas de Língua Inglesa para o Jornalismo e de Inglês para Comunicação Empresarial foram lecionadas no segundo semestre de 2017. Cada disciplina teve como objetivo o desenvolvimento de habilidades linguísticas diversas - ao passo que a disciplina de Jornalismo trabalhou com a compreensão escrita, desenvolvendo a habilidade leitora nos alunos, a disciplina de Matemática Empresarial trabalhou com a compreensão e a produção oral, desenvolvendo as habilidades de listening e speaking. Os objetivos de cada disciplina nortearam a seleção de materiais, a dinâmica de sala de aula e as formas e critérios de avaliação. Apesar da heterogeneidade linguística presente em cada turma, podemos concluir que as disciplinas cumpriram com seus objetivos, atendendo as necessidades específicas de cada contexto de ensino-aprendizagem.

Palavras-chave: Ensino de inglês para fins específicos; Compreensão escrita no ensino de língua inglesa; Compreensão e produção oral no ensino de língua inglesa.

\begin{abstract}
The aim of this paper is to report the teaching of English for Specific Purposes in two undergrad courses of Universidade Estadual de Londrina, in Brazil: Journalism and Business Mathematics. The subjects of English for Journalism and English for Business Communication were taught during the second semester of 2017. Each subject aimed at developing different linguistic abilities - while the subject of Journalism worked with the reading comprehension skill, the subject of Business Mathematics worked with the skills of oral comprehension (listening) and oral production (speaking). The aims of each subject guided the selection of materials, the classroom dynamics, and the assessment types and criteria. Despite the linguistic heterogeneity of the groups, we can conclude that both the subjects accomplished their objectives, meeting the specific needs of each teaching-learning context.

Keywords: English for Specific Purposes; reading comprehension in English language teaching; oral comprehension and oral production in English language teaching.
\end{abstract}

\section{Introdução}

O inglês instrumental, ou inglês para fins específicos (English for Specific Purposes, doravante ESP) pode ser definido como o ensino-aprendizagem de inglês como língua estrangeira ou como segunda língua que tem como objetivo a capacitação dos aprendizes para o uso da língua em uma área específica (PALTRIDGE \& STARFIELD, 2013). Para Paltridge e Starfield,

uma das características-chave de cursos de ESP é o fato de que o conteúdo e os objetivos do curso orientam-se para as necessidades específicas de seus aprendizes. Cursos de ESP têm

\footnotetext{
1 Professora Doutora do curso de Letras-Inglês da Universidade Estadual de Londrina (Departamento de Letras Estrangeiras Modernas, Centro de Letras e Ciências Humanas). E-mail: elisliberatti@hotmail.com
} 
como foco a língua, as habilidades e os gêneros adequados voltados a atividades específicas que os alunos devem ser capazes de realizar em inglês (2013, p. 2, tradução minha²).

Com objetivo primário de comunicação envolvendo duas línguas diferentes em áreas como comércio e tecnologia, o ensino de ESP foi se expandindo e conquistando novos campos, tais como: inglês para fins acadêmicos, inglês para fins ocupacionais, inglês para fins vocacionais, inglês para fins médicos, inglês para negócios, inglês para fins jurídicos e inglês para fins socioculturais (BELCHER, 2009, apud PALTRIDGE; STARFIELD, 2013, p.02)

Em contraste com o ensino de inglês geral, a análise das necessidades específicas dos alunos volta-se à vida profissional ou acadêmica do aprendiz, ao invés de focar em interesses pessoais ou temas gerais. Consequentemente, o ensino de ESP aborda também a análise do uso da língua e textos com os quais os alunos irão se deparar em suas situações profissionais ou acadêmicas (BASTURKMEN, 2010), como apontam Dudley-Evans e St John:

os principais interesses do ESP sempre foram e continuam sendo a análise de necessidades, a análise textual e o preparo de alunos para se comunicarem de maneira eficiente nas tarefas prescritas em suas situações de estudo ou trabalho (1998, p. 1, apud BASTURKMEN, 2010, p. 2, tradução minha ${ }^{4}$.

Para Nunan (2004), o ensino de ESP é um subcomponente importante do ensino de inglês geral, que tem suas próprias abordagens referentes a desenho de currículo, desenho de materiais, pedagogia, avaliação e pesquisa. $\mathrm{O}$ ensino de inglês para fins específicos na Universidade Estadual de Londrina (UEL), no momento de confecção deste artigo, atende os seguintes cursos de graduação: Jornalismo (Centro de Comunicação e Expressão), Matemática Empresarial (Centro de Ciências Exatas), Secretariado Executivo (Centro de Estudo Sociais Aplicados), Química (Centro de Ciências Exatas) e Ciências da Informação (Centro de Comunicação e Expressão).

Nesse sentido, o objetivo deste artigo é relatar a experiência de ensino de inglês para fins específicos para dois desses cursos: Jornalismo e Matemática Empresarial. Ambas as disciplinas foram ministradas durante o segundo semestre de 2017, e têm ementas que enfocam o desenvolvimento de diferentes habilidades linguísticas. Enquanto a disciplina de inglês instrumental para Jornalismo visa trabalhar com estratégias de leitura e compreensão de textos na área jornalística, a disciplina de inglês instrumental para Matemática Empresarial tem como objetivo trabalhar a compreensão e produção oral em contextos empresariais. Na próxima seção, discorremos de maneira mais detalhada sobre os programas de cada disciplina, para então fazermos o relato de experiência, no qual detalhamos as vivências mais relevantes de ensino ocorridas em cada contexto, traçando paralelos entre elas.

\section{0 ensino de inglês para fins específicos para o curso de Jornalis- mo}

No curso de jornalismo da UEL, o inglês instrumental é ensinado na disciplina denominada "Língua inglesa para o jornalismo". Com oferta para alunos do segundo ano do curso, acontece durante o segundo semestre letivo e tem carga horária de 30 horas-aula. Os objetivos da disci-

\footnotetext{
2 A key feature of an ESP course is that the content and aims of the course are oriented to the specific needs of the learners. ESP courses, then, focus on the language, skills, and genres appropriate to the specific activities the learners need to carry out in English.

${ }^{3}$ Para mais informações, consulte Belcher (2009).

${ }^{4}$ The main concerns of ESP have always been, and remain, with needs analysis, text analysis, and preparing learners to communicate effectively in the tasks prescribed by their study or work situation.
} 
plina são: i. desenvolver / aprimorar estratégias de leitura para a compreensão de textos em língua inglesa na área de Jornalismo; ii. ampliar vocabulário referente a textos jornalísticos e iii. desenvolver consciência crítica dos usos da linguagem em textos jornalísticos.

De caráter teórico, a disciplina trabalha com leitura e compreensão de textos da área de jornalismo, abordando os seguintes gêneros textuais: resumo de artigo científico, artigo acadêmico, notícias, charges e tirinhas. Estratégias de leitura são aplicadas a esses gêneros, tais como uso de conhecimento prévio, uso de informação não-verbal, reconhecimento de gêneros textuais, predição, Skimming para compreensão da ideia geral do texto, Scanning para compreensão de informações específicas do texto, inferência e reconhecimento de cognatos e palavras-chave. Além disso, as seguintes estruturas gramaticais são trabalhadas, sempre visando o objetivo do curso: tempos verbais, verbos modais, grupos nominais, referência contextual e marcadores de discurso. Quanto às formas de avaliação, temos a aplicação de provas escritas individuais, trabalhos escritos em duplas e apresentação de seminários em grupos.

\section{O ensino de inglês para fins específicos para o curso de Matemáti- ca Empresarial}

Diferentemente da disciplina de ESP para o curso de Jornalismo, a disciplina "Inglês para comunicação empresarial" teve sua primeira oferta no segundo semestre de 2017, o que significa que até o momento de confecção deste artigo a oferta havia ocorrido apenas para uma turma do curso, no caso, alunos do quarto ano.

De caráter prático, a disciplina também ocorre durante o segundo semestre letivo e tem carga horária de 60 horas-aula. Com o objetivo de desenvolver / aprimorar estratégias de compreensão e produção oral em contextos empresariais, a disciplina aborda questões de compreensão e produção oral para situações de comunicação em contextos empresariais (apresentação, socialização, telefonema, reunião e negociação), além de trabalhar as seguintes estruturas léxicogramaticais: aspectos e tempos verbais, grupos nominais, referência textual e marcadores de discurso.

As formas de avaliação abrangem provas individuais escritas, com itens léxico-gramaticais relevantes à comunicação em contexto empresarial; provas orais, com itens discursivos relevantes à comunicação em contexto empresarial; e apresentação de trabalho, com base em temas selecionados pela professora, a fim de verificar a assimilação de estratégias de compreensão e produção oral em contextos empresariais e do conteúdo específico abordado durante as aulas.

Fica clara a diferença de objetivos entre as duas disciplinas aqui citadas: além de trabalharem com gêneros textuais diversos, a disciplina do curso de Jornalismo tem como foco a compreensão escrita, isto é, o desenvolvimento da habilidade de leitura em língua inglesa, ao passo que a disciplina do curso de Matemática Empresarial tem como foco a compreensão e produção orais, ou seja, o desenvolvimento das habilidades de listening e speaking em língua inglesa, respectivamente. Isso posto, passamos ao relato de experiência de ensino de ambas as disciplinas, ministradas em 2017 pela docente Elisângela Liberatti, autora deste relato.

\section{Relato de experiência}

No primeiro dia de aula, tanto para o curso de Jornalismo quanto para o curso de Matemática Empresarial, foi aplicado teste diagnóstico para avaliar o nível linguístico dos alunos. O teste diagnóstico mostrou considerável heterogeneidade linguística em ambas as turmas; porém foi na turma de Jornalismo que se observou maior discrepância, o que pode ter se dado pelo fato de haver 20 alunos na turma, ao passo que na turma de Matemática Empresarial havia apenas 4 alunos.

A heterogeneidade linguística não foi uma barreira em nenhum dos cursos, uma vez que a

https://periodicos.unifap.br/index.php/letras

Macapá, v. 9, n. 3, $2^{\circ}$ sem., 2019 
professora, em algumas ocasiões, buscou colocar em pares alunos com maior e menor habilidade linguística, para que os alunos com mais conhecimento da língua pudessem auxiliar os com menos conhecimento, levando-se em consideração a habilidade de compreensão textual. Além disso, o conteúdo e os materiais selecionados para o curso, abaixo descritos, foram nivelados levando em consideração os alunos básicos/préintermediários, nível mais baixo apontado pela avaliação diagnóstica.

É importante destacar também que ambas as disciplinas foram ministradas primordialmente em língua portuguesa, devido ao nível de proficiência em língua inglesa de parte dos alunos. Mesmo assim, a docente por vezes alternava algumas instruções em inglês e em português, verificando se os alunos haviam entendido as instruções em língua inglesa; em caso negativo, as mesmas instruções eram repetidas em português.

No decorrer do curso, a prática acima descrita foi se torando mais recorrente, especialmente na disciplina de Inglês para Comunicação Empresarial, uma vez que a disciplina tem duração de 1 ano, diferentemente da disciplina de Língua Inglesa para o Jornalismo, com duração de 1 semestre. Além disso, os alunos do curso de Matemática tinham um nível linguístico geral mais alto do que os alunos do curso de Jornalismo. Por fim, os diferentes propósitos de cada uma das disciplinas influenciou tal prática: ao passo que a disciplina de Língua Inglesa para o Jornalismo tem como enfoque o desenvolvimento da habilidade de compreensão leitora, a disciplina de Inglês para Comunicação Empresarial tem como enfoque o desenvolvimento da habilidade de compreensão e produção oral, o que justifica as tentativas de interações orais durante as instruções em sala de aula.

No curso de Jornalismo, iniciamos a disciplina trabalhando de maneira significativa com o livro "Leitura em língua inglesa: uma abordagem instrumental" (2005). Dessa forma, trouxemos para a sala de aula os seguintes conteúdos: reconhecimento de gêneros textuais, objetivos de leitura e níveis de compreensão, cognatos, conhecimento prévio, Skimming, Scanning, informação não-verbal, inferência contextual, palavras-chave, grupos nominais, referência pronominal e marcadores discursivos.

O conhecimento relativo a esses conteúdos embasou os gêneros jornalísticos que seriam trabalhados a seguir, a saber: notícia jornalística, charge, cartum, tira cômica, resumo científico e artigo acadêmico - o resumo científico e o artigo acadêmico abordaram apenas textos do campo disciplinar do Jornalismo.

$\mathrm{Na}$ notícia jornalística, trabalhamos com a estrutura do gênero notícia (técnica da pirâmide invertida ${ }^{5}$. Analisamos textos com base nessa técnica de estruturação textual ao identificarmos aspectos como "quem fez o quê, quando, onde, por quê, como", além de aplicarmos as estratégias de leitura à compreensão escrita de textos do gênero. Os alunos trabalhavam em duplas ou individualmente para fazerem exercícios de interpretação de texto trazidos pela professora, e depois havia discussão com a turma toda.

Já em relação aos gêneros charge, cartum e tira cômica, foram trabalhados os aspectos dos gêneros de maneira não fragmentada, isto é, a professora apresentou os três gêneros, suas características, semelhanças e diferenças, além de trazer exemplos em inglês. A professora diferenciou charge e cartum, trouxe aspectos político-culturais ligados a charges dos Estados Unidos e do Brasil e apontou a importância de o profissional saber fazer uma leitura adequada desses gêneros, conhecendo elementos tanto do texto verbal quanto do texto não-verbal.

Foram feitas análises de cartuns, charges e tiras cômicas, apresentados símbolos utilizados em charges dos Estados Unidos e atividades de análise e interpretação textual utilizando esses gêneros. As discussões foram ricas, demonstram leitura e pensamento crítico dos alunos, e, ao

\footnotetext{
5 Para mais informações, vide http://estudosdejornalismo.blogspot.com/2008/05/pirmide-invertida-e-o-lide.html e http://www.ufrgs.br/alcar/encontros-nacionais-1/9o-encontro-2013/artigos/gt-historia-da-midia-digital/o-quetemos-para-hoje-piramide-invertida-no-jornalismo-on-linee.
} 
final do tópico, os estudantes produziram seus próprios textos, para serem inseridos em uma tira apresentada pela professora.

Os gêneros resumo científico e artigo acadêmico também foram abordados de maneira conjunta. Com enfoque em textos acadêmicos da área do Jornalismo, foi apresentada aos alunos a estrutura de um resumo de artigo científico em inglês, a característica dos itens que compõem o resumo e seu objetivo. Primeiramente com o grupo todo, e posteriormente em duplas, os alunos analisaram alguns resumos, apontando nos textos onde estavam a introdução, os objetivos, a metodologia, os resultados e a conclusão, além de analisarem se todos os resumos trazidos pela professora estavam escritos de acordo com as convenções do gênero, previamente apresentadas.

A professora apresentou a estrutura de um artigo científico, trouxe técnicas para tornar eficiente a leitura de artigos, discorreu sobre a importância de se realizar uma leitura estratégica do gênero e trouxe alguns excertos de artigos acadêmicos da área. Além disso, foram realizadas atividades nas quais os alunos deveriam aplicar as estratégias de leitura estudadas no início da disciplina a um excerto de artigo.

Quanto às formas de avaliação da disciplina "Língua inglesa para o jornalismo", tivemos apresentações de dois seminários em grupos (em português, uma vez que o foco não era o desenvolvimento da produção oral, e sim da compreensão escrita), realização de duas provas escritas individuais e entrega de um trabalho escrito em grupos.

Quanto ao seminário I, a cada grupo foi designada uma estratégia de leitura, e o grupo deveria explicar a estratégia em questão, além de trazer um texto da esfera jornalística (em inglês) para a turma, conduzindo com a sala uma análise do texto segundo a estratégia de leitura apresentada. Ao final, deveriam propor uma discussão crítica em torno do tema trazido.

Já para o seminário II, os alunos deveriam discorrer sobre o gênero notícia jornalística, apresentando à turma uma notícia atual e em inglês. O grupo deveria pedir aos alunos que identificassem no texto algumas informações trazidas pela técnica da pirâmide invertida do jornalismo, apontar em qual pessoa do discurso o texto estava escrito, dizer como as seções estavam divididas, apontar citações diretas e dizer sua função e importância, entre outros aspectos. Além disso, deveriam apresentar um resumo (em inglês) do texto trabalhado ${ }^{6}$.

As provas escritas abordaram os conteúdos trabalhados em sala de aula. Com textos de análise em língua inglesa, as questões da prova foram formuladas em língua portuguesa, e os alunos poderiam escolher se gostariam de respondê-las em inglês ou português, uma vez que o foco da disciplina era o desenvolvimento da compreensão escrita em língua inglesa, e não o desenvolvimento da produção escrita.

No trabalho escrito, os alunos deveriam, em duplas, escolher um texto do gênero notícia jornalística que fosse atual e com aproximadamente 2500 toques, ou seja, não muito longo nem muito curto. Após a seleção da notícia, deveriam analisa-la minuciosamente segundo três estratégias de leitura já trabalhadas em sala de aula - as estratégias poderiam ser escolhidas pelas próprias duplas. Os alunos deveriam deixar claro quais estratégias foram selecionadas e também sua aplicação na análise textual.

$\mathrm{Na}$ disciplina "Inglês para comunicação empresarial", iniciamos com vocabulário básico referente à área de negócios ${ }^{7}$ : partes de uma empresa, benefícios, negociação, verbos frasais, marketing, comércio internacional e reuniões. A seguir, passamos a trabalhar com outro material de

\footnotetext{
${ }^{6}$ Apesar de a disciplina ter como objetivo o desenvolvimento da compreensão escrita, e não a produção, senti que poderia exigir um pouco mais dos alunos. Minha hipótese se confirmou: por estarem em equipes linguisticamente heterogêneas, os alunos conseguiram entregar resumos que traziam o cerne dos textos apresentados, demonstrando bom entendimento do texto.

7 Conteúdo trabalhado por meio do E-book "Inglês Empresarial" (Copyright Englishvox2010). Disponível em: http://static.portaleducacao.com.br/arquivo/manual/12012012172452ingles_empresarial.pdf
} 
inglês para negócios ${ }^{8}$, abrangendo os seguintes temas: self-introduction, apologizing, asking for directions, requesting materials, business calls, job interviews, discussions, meetings, formal and informal expressions, email, organizations, types of companies.

O próximo material trabalhado foi o livro "English for Business Communication" de Simon Sweeney (1997, Cambridge University Press). Com conteúdo abordando desde diversidade cultural e socialização a telefonemas, apresentações, reuniões e negociações, o livro permitiu o foco em conversação, objetivo da disciplina. Além do que já havia sido previsto no programa da disciplina, o vocabulário e a gramática também foram trabalhados conforme dúvidas foram surgindo por parte dos alunos. Sempre que possível, a professora buscou utilizar uma metodologia ativa, tendo os alunos no centro do processo de aprendizagem, a fim de desenvolver sua autonomia. Para isso, após o imput linguístico necessário à produção oral, a professora organizava os alunos em pares e passava uma tarefa com foco na conversação. De tempos em tempos, fazia o monitoramento dos estudantes, ajudando-os quando necessário e, ao final das discussões, trazia questões importantes relativas a seu desempenho - como correções léxicogramaticais e sociolinguísticas. Por ser um grupo pequeno (quatro alunos), atividades com a turma toda também aconteceram em algumas ocasiões.

Uma apresentação de trabalho, duas provas orais e uma prova escrita compuseram as avaliações aplicadas durante o curso. Para a apresentação do trabalho, os alunos deveriam, em duplas, criar um diálogo envolvendo uma situação comunicativa empresarial e trazer para a turma em formato de produção oral, em língua inglesa. A professora pediu que trabalhassem com algum tema já abordado até o momento e que tentassem fazer a simulação de modo que ficasse a mais realística e natural quanto possível.

A forma de avaliação que mais demonstrou o progresso dos alunos foram as provas orais. Diferentemente da apresentação do trabalho, durante as provas orais os alunos não puderam ter acesso a nenhum tipo de material. Isso permitiu mensurar de maneira fidedigna se o objetivo da disciplina foi atingido, isto é, se os alunos estavam aptos a se comunicarem oralmente em situações ligadas a contextos empresariais.

A primeira prova oral foi assim dividida: no primeiro exercício, os alunos deveriam, individualmente, escolher um dentre os quatro tópicos apresentados e falar por um minuto, até a professora interrompê-los. Os tópicos eram de nível pré-intermediário, e o input necessário à realização da tarefa havia sido trabalhado previamente, em sala de aula. Para o segundo exercício, os alunos deveriam, também individualmente, escolher uma entre três figuras apresentadas e falar sobre a imagem selecionada, também por um minuto, até a professora interrompê-los. Para o exercício dois, os estudantes precisavam fazer uma negociação, pois não poderiam escolher e falar sobre a mesma figura.

No exercício três, foram apresentados dois infográficos e os alunos, agora em dupla, deveriam escolher um deles e comentar sobre o conteúdo do infográfico de dois a três minutos, também até haver interrupção por parte da professora. Por fim, no exercício quatro, também em duplas, os alunos deveriam decidir quem faria o papel do visitante e quem faria o papel do recepcionista em uma situação empresarial e criar um diálogo com base no gráfico apresentado, falando de dois a três minutos até serem interrompidos pela professora.

Para a segunda prova oral, os alunos também foram organizados em duplas e foram apresentados a quatro situações-problema relativas à compra de produtos ou serviços. Deveriam escolher duas das situações e simular uma conversação por meio do telefone, sendo que em uma das situações um dos alunos seria o cliente e o outro, a empresa, e depois deveriam inverter papeis para a situação seguinte. Lidar com problemas relativos a produtos/serviços e comunicar-se via telefone já haviam sido tópicos trabalhados em sala de aula. Para as provas orais, os alunos

\footnotetext{
${ }^{8}$ Conteúdo trabalhado por meio do website Engoo - 25-minute online Enlglish Lessons (Materiais básicos de Inglês para Negócios). Disponível em: https://engoo.com.br/materiais-do-curso/ingles-para-negocios.
} 
foram avaliados de acordo com o seguinte critério: muito bom (100), bom (80), suficiente (60), insuficiente (40), muito insuficiente (20).

A prova escrita, que ocorreu ao final do curso, teve como objetivo a escrita de um e-mail envolvendo uma situação simulada. O aluno, como chefe de uma empresa, deveria marcar com um representante uma viagem a trabalho, acertando os detalhes e passando algumas informações relevantes. Mesmo com foco em compreensão e produção oral, julguei importante trabalhar com os alunos alguns aspectos básicos de confecção de e-mails em língua inglesa, uma vez que esta prática é corriqueira no meio empresarial, e a língua utilizada para qualquer comunicação internacional é a língua franca.

Para ambas as disciplinas, ao final do curso, foi aplicado um questionário de avaliação da disciplina. As questões abordadas no questionário foram:

i. $\quad$ O curso atendeu as suas expectativas?

ii. Você ficou satisfeito com a didática utilizada pela professora?

iii. As aulas estavam bem organizadas e preparadas?

iv. As instruções e explicações foram claras?

v. Os materiais selecionados pela professora estavam de acordo com suas expectativas e com o objetivo do curso?

vi. As avaliações e seus critérios foram justos e bem aplicados?

vii. O que você acrescentaria e/ou mudaria em relação ao conteúdo das aulas?

De maneira geral, os alunos ficaram satisfeitos com as disciplinas e o andamento das aulas; porém, acrescentaram que gostariam de ter tido mais tempo de aulas, para que pudessem trabalhar de forma mais extensa e aprofundada os tópicos trazidos pela professora. Após relato de duas experiências bastante diversas com o ensino de inglês para fins específicos para estudantes universitários, buscamos ter demonstrado que os objetivos de cada disciplina, trazidos nos programas acadêmicos, guiam a prática do professor, bem como a escolha de materiais e procedimentos de ensino.

\section{Considerações finais}

O ensino de inglês instrumental (inglês para fins específicos - ESP) pode ocorrer em contextos diversos e trabalhar diferente(s) habilidade(s) linguística(s), de acordo com a análise das necessidades comunicativas dos alunos. Para Basturkmen,

No ensino de inglês para fins específicos, o aluno é visto como um aprendiz da língua engajado em buscas acadêmicas, profissionais ou ocupacionais, e utiliza o inglês como um meio para executar tais buscas. [...] Nesta situação, o desenvolvimento da língua é visto como um meio para atingir um objetivo, e não como o objetivo em si, e os alunos podem ficar facilmente desmotivados por conteúdos que não sejam diretamente relevantes a seus reais objetivos. O professor / desenvolvedor de cursos de inglês para fins específicos precisa descobrir quais os objetivos linguísticos de seus alunos [...] e garantir que os conteúdos do curso estejam de acordo com esses objetivos (2010, p. 8, tradução minha').

\footnotetext{
9 In ESP the learner is seen as a language learner engaged either in academic, professional or occupational pursuits and who uses English as a means to carry out those pursuits. [...] In this situation, language development is seen as the means to the ends but not as the end in itself, and the learners can easily become de-motivated by language course content that does not appear directly relevant to their real world objectives. The ESP teacher/course developer needs to find out what the language-based objectives of the students are [...] and ensure that the content of the ESP course works towards them.
} 
No ensino de ESP, a língua é vista como um instrumento para se alcançar determinado(s) objetivo(s), ou seja, não deve ser aprendida pela língua em si, mas como forma de atingir um fim específico que requer competências e habilidades linguísticas específicas (BASTURKMEN, 2010, p. 7-8). Nesse sentido, no curso de Jornalismo, trabalhamos com textos da área, de forma a buscar desenvolver a habilidade de compreensão escrita em gêneros como notícia, charges e artigos acadêmicos. As avaliações foram pensadas de modo a mensurar o desenvolvimento dessa habilidade específica, ou seja, a habilidade de leitura em língua inglesa. Dessa forma, a língua foi utilizada como um instrumento para atingir o objetivo da disciplina, ou seja, a compreensão de textos em língua inglesa na área do Jornalismo, com ampliação de vocabulário referente a textos jornalísticos e desenvolvimento da consciência crítica dos usos da linguagem em textos da área.

Já no curso de Matemática, o foco foi trabalhar a compreensão e produção oral em voltadas à comunicação empresarial. Assim, os alunos praticaram com bastante frequência atividades de listening em contextos empresariais; trabalharam com greetings e self-introduction; simularam (oralmente) apresentações, reuniões, consultorias e negociações; trabalharam com níveis de fala (formal, neutro, informal) e conversas telefônicas; entre outros.

As avaliações voltaram-se à compreensão e produção oral, com provas orais e apresentação, além de uma prova escrita, que abordou a confecção de um e-mail corporativo em língua inglesa. Do mesmo modo que no curso de Jornalismo, a língua foi utilizada como instrumento para atingir o objetivo da disciplina, isto é, desenvolver estratégias de compreensão e produção oral em contextos empresariais. Como podemos observar, os objetivos de cada uma das disciplinas aqui descritas delinearam a seleção de materiais, as dinâmicas de sala de aula e as formas e critérios de avaliação, sempre tendo em vista as necessidades dos alunos de cada curso.

Nesse sentido, trazemos a tabela abaixo, na qual fazemos uma análise contrastiva entre as duas disciplinas ministradas em 2017:

\begin{tabular}{|l|l|l|}
\cline { 2 - 3 } \multicolumn{1}{c|}{} & \multicolumn{2}{c|}{ DISCIPLINAS } \\
\cline { 2 - 3 } \multicolumn{1}{c|}{} & Língua Inglesa para o Jornalismo & Inglês para Comunicação Empresarial \\
\hline Quantidade de alunos & 20 & 4 \\
\hline Nabilidade linguística trabalhada & Compreensão leitora (Reading) & $\begin{array}{l}\text { Compreensão e produção oral (listening } \\
\text { e speaking) }\end{array}$ \\
\hline $\begin{array}{l}\text { Heterogeneidade linguística } \\
\text { entre alunos do grupo }\end{array}$ & Básico/pré-intermediário & Intermediário/intermediário-avançado \\
\hline $\begin{array}{l}\text { Interações orais em inglês (du- } \\
\text { rante instruções em sala de aula, } \\
\text { explicações, etc.) }\end{array}$ & $\begin{array}{l}\text { Menor interação tanto aluno- } \\
\text { professor quanto professor-aluno, } \\
\text { devido ao nível linguístico e ao pro- } \\
\text { pósito da disciplina (desenvolvimen- } \\
\text { to da habilidade de compreensão } \\
\text { leitora) }\end{array}$ & $\begin{array}{l}\text { Maior interação tanto aluno-professor } \\
\text { linguístico e ao propósito desoro disciplina } \\
\text { (desenvolvimento da habilidade de } \\
\text { compreensão e produção oral) }\end{array}$ \\
\hline
\end{tabular}

\section{Referências}

BASTURKMEN, Helen. Developing Courses in English for Specific Purposes. Basingstoke: Palgrave Macmillan, 2010.

BELCHER, Diane. What ESP is and can be: An introduction. In: BELCHER, Diane (Ed.). English for Specific Purposes in Theory and Practice. Ann Arbor, MI: University of Michigan Press, 2009, p. 1-20.

PALTRIDGE, Brian; STARFIELD, Sue (Eds.). The Handbook of English for Specific Purposes. Boston: Wiley-Blackwell, 2013.

DUDLEY-EVANS, Tony; ST JOHN, Maggie Jo. Developments in English for Specific Purposes. Cambridge: Cambridge University Press, 1998.

NUNAN, David. Task-Based Language Teaching. Cambridge: Cambridge University Press, 2004. 
SOUZA, Adriana Grade Fiori; ABSY, Conceição A.; COSTA, Gisele Cilli; MELLO,

Leonilde Favoreto. Leitura em Lingua Inglesa: uma abordagem instrumental. São Paulo: DISAL, 2005. 